\title{
Práticas culturais na entressafra da soja para o controle de Pratylenchus brachyurus
}

\author{
Henrique Debiasi ${ }^{(1)}$, Julio Cezar Franchini(1), Waldir Pereira Dias ${ }^{(1)}$, \\ Edison Ulisses Ramos Junior ${ }^{(2)}$ e Alvadi Antonio Balbinot Junior ${ }^{(1)}$
}

\begin{abstract}
(1)Embrapa Soja, Rodovia Carlos João Strass, Distrito de Warta, Caixa Postal 231, CEP 86001-970 Londrina, PR, Brasil. E-mail: henrique.debiasi@embrapa.br, julio.franchini@embrapa.br, waldir.dias@embrapa.br, alvadi.balbinot@embrapa.br (2)Embrapa Agrossilvipastoril, Rodovia MT-222, Km 2,5, CEP 78550-970 Sinop, MT, Brasil. E-mail: edison.ramos@embrapa.br
\end{abstract}

Resumo - O objetivo deste trabalho foi avaliar o potencial de práticas culturais, adotadas na entressafra, para reduzir a população e os danos causados por Pratylenchus brachyurus em soja. Realizou-se um experimento em área naturalmente infestada, nas safras 2010/2011, 2011/2012 e 2012/2013, em Vera, MT. Os tratamentos foram: milheto (Pennisetum glaucum) 'ADR 7010' (2010/2011) e 'ADR 300' (nas entressafras seguintes); milho (Zea mays) 'BRS 1010' (2010/2011) e 'GNZ 2005' (nas entressafras seguintes); braquiária ruziziensis (Urochloa ruziziensis); capim-marandu (U. brizantha 'Marandu'); crotalária (Crotalaria ochroleuca); C. juncea; C. spectabilis; C. spectabilis + milheto 'ADR 300' (de 2011/2012 em diante); alqueive mecânico (duas gradagens + herbicida); pousio (sem controle de ervas daninhas); e testemunha (alqueive químico, com aplicação de herbicida). $\mathrm{O}$ alqueive mecânico, as crotalárias e $C$. spectabilis + milheto reduziram a população do nematoide antes da semeadura e nos estádios iniciais da soja. Após a colheita da soja, a população de nematoides não diferiu entre os tratamentos, o que indica que a multiplicação destes na cultura foi maior nos manejos com menor população inicial. O uso de $C$. spectabilis, milheto e $C$. spectabilis + milheto contribuíram para as maiores produtividades de soja. O cultivo de C. spectabilis, solteira ou consorciada ao milheto 'ADR 300', é a melhor opção para reduzir a população e os danos causados por $P$. brachyurus à soja na entressafra.

Termos para indexação: Glycine max, gradagem, nematoide, plantas de cobertura, pousio.

\section{Cultural practices during the soybean off-season for the control of Pratylenchus brachyurus}

\begin{abstract}
The objective of this work was to evaluate the potential of cultural practices, adopted during the soybean off-season, to reduce the Pratylenchus brachyurus population and damages to soybean. An experiment was carried out in a naturally-infested agricultural field, in the growing seasons of 2010/2011, 2011/2012, and 2012/2013, in the municipality of Vera, in the state of Mato Grosso, Brazil. The treatments were: 'ADR 7010' (2010/2011) and 'ADR 300' pearl millet (Pennisetum glaucum) (in the following offseasons); 'BRS 1010' (2010/2011) and 'GNZ 2005' corn (Zea mays) (in the following off-seasons); Congo grass (Urochloa ruziziensis); 'Marandu' palisade grass (U. brizantha 'Marandu'); slender leaf rattlebox (Crotalaria ochroleuca); sunn hemp (C. juncea); showy rattlebox (C. spectabilis); C. spectabilis + 'ADR 300' pearl millet (from 2011/2012 onwards); fallow (weed control by two diskings + herbicide); fallow (without weed control); and control (fallow with weed control by herbicide). Fallow (two diskings + herbicide), rattlebox species, and C. spectabilis + pearl millet reduced the nematode population before planting and during the early soybean stages. After soybean harvest, the nematode population did not differ among treatments, which indicates that the nematode multiplication on the crop was higher in treatments with lower initial population. The use of C. spectabilis, pearl millet, and C. spectabilis + pearl millet favored higher soybean yields. The cultivation of $C$. spectabilis - alone or associated with 'ADR 300' pearl millet - is the best suitable option to reduce the $P$. brachyurus population and damages to soybean in the off-season.
\end{abstract}

Index terms: Glycine max, disking, nematode, cover crops, fallow.

\section{Introdução}

O nematoide-das-lesões-radiculares (Pratylenchus brachyurus) tem causado danos econômicos elevados à cultura da soja no Brasil, principalmente na região Centro-Oeste, com perdas de produtividade de até 50\% (Franchini et al., 2014). Das 68 espécies de Pratylenchus spp. consideradas válidas (Castillo \& 
Vovlas, 2007), P. brachyurus é a única relevante para a soja (Dias et al., 2010). Trata-se de um nematoide endoparasita, migrador e polífago que, em razão da alimentação, movimentação e injeção de toxinas no interior dos tecidos, provoca danos às raízes da soja (Goulart, 2008). Pratylenchus brachyurus apresenta ampla disseminação no País, especialmente na região Centro-Oeste (Ribeiro et al., 2010). A expansão da soja em áreas de solos arenosos, combinada à utilização de cultivares muito suscetíveis e à semeadura de espécies vegetais hospedeiras como o milho e o algodão, na entressafra da soja, são os fatores que melhor explicam o aumento da importância do nematoide para a cultura (Dias et al., 2010).

Em consequência da indisponibilidade de cultivares de soja resistentes e da inconsistência dos resultados alcançados com o uso de nematicidas, a rotação ou a sucessão da soja com culturas não hospedeiras ou com hospedeiras desfavoráveis são os métodos mais promissores de manejo de $P$. brachyurus. No entanto, a ampla gama de hospedeiros de $P$. brachyurus dificulta a seleção de espécies vegetais para a composição de esquemas de rotação ou sucessão (Goulart, 2008). A capacidade de multiplicar $P$. brachyurus por diferentes espécies vegetais tem sido extensivamente estudada em casa de vegetação (Inomoto et al., 2006, 2007; Machado et al., 2007; Inomoto, 2011; Queiróz et al., 2014). Estes trabalhos indicam que Crotalaria spectabilis Roth, C. breviflora DC. e C. ochroleuca G. Don são as melhores espécies para a redução da população de $P$. brachyurus, com fatores de reprodução (R) iguais ou próximos de zero. Alguns genótipos de milheto (Pennisetum americanum L.) e girassol (Helianthus annuus L.), além do guandu (Cajanus cajan L.), aveia-preta (Avena strigosa Schreb.) e trigo (Triticum aestivum L.), também são considerados hospedeiros desfavoráveis $(\mathrm{R}<1)$. Porém, a maior parte dos híbridos de milho (Zea mays L.) e sorgo (Sorghum bicolor L.), além de gramíneas forrageiras perenes, como Urochloa ruziziensis (R. Germ \& Evrard), U. brizantha (Stapf) e Panicum spp. L. são hospedeiros favoráveis ao nematoide. É importante destacar que, em condições de campo, os efeitos destas espécies sobre o nematoide podem ser diferentes. Além de diferenças em relação a fatores ambientais, como temperatura e disponibilidade hídrica, os experimentos em casa de vegetação não levam em consideração os efeitos das culturas sobre atributos do solo, que podem interferir direta ou indiretamente na população e nos danos dos nematoides (Costa et al., 2014). Ademais, a permanência das espécies vegetais em campo é, em geral, superior à duração dos ensaios de casa de vegetação, o que pode alterar o potencial de multiplicação do nematoide (Inomoto, 2011).

Outra prática com potencial para o controle de P. brachyurus, mas ainda pouco estudada, é o alqueive, que consiste em manter a área por certo período sem qualquer vegetação, sobretudo com revolvimento do solo por meio de aração e/ou gradagem. Assim, os nematoides morrem por inanição, dessecação e pela ação direta da luz solar (Inomoto, 2008). Porém, o alqueive pode resultar na degradação da qualidade do solo no sistema plantio direto e, dessa forma, diminuir a tolerância da soja aos danos do nematoide.

O objetivo deste estudo foi avaliar o potencial de práticas culturais, adotadas na entressafra, em reduzir a população e os danos causados por $P$. brachyurus em soja.

\section{Material e Métodos}

O experimento foi instalado em fevereiro de 2010 e conduzido durante as safras 2010/2011, 2011/2012 e 2012/2013, em área pertencente à Fazenda Dacar, com histórico de perdas elevadas de produtividade de soja causadas por P. brachyurus, no município de Vera, região médio-norte de Mato Grosso $\left(12^{\circ} 08^{\prime} 38^{\prime \prime} \mathrm{S}\right.$, $55^{\circ} 10^{\prime} 56^{\prime \prime} \mathrm{W}$, à $320 \mathrm{~m}$ de altitude). Segundo a classificação de Köppen-Geiger, o clima da região é do tipo Aw (tropical quente e úmido, com estação seca definida entre maio e agosto). A temperatura média anual é de $24^{\circ} \mathrm{C}$, com temperatura média máxima de $25^{\circ} \mathrm{C}$ em outubro, e média mínima de $21,9^{\circ} \mathrm{C}$ em julho. A precipitação média anual é de $2.373 \mathrm{~mm}$, e março é o mês mais chuvoso (485 mm), e julho, o mais seco (2 mm).

O solo foi classificado como Latossolo Vermelho-Amarelo distrófico, de textura arenosa (130, 20 e $850 \mathrm{~g} \mathrm{~kg}^{-1}$ de argila, silte e areia, respectivamente, na camada de $0-0,2 \mathrm{~m}$ de profundidade). A área foi desmatada em 2004 e cultivada com arroz, nos dois primeiros anos, e com a sucessão soja/milheto nas demais safras. Os valores médios de alguns atributos químicos e físicos do solo (camada de 0-0,2 m), antes da instalação do experimento, foram: $\mathrm{pH}$ em $\mathrm{CaCl}_{2}$, 5,02; C orgânico, 16,8 $\mathrm{g} \mathrm{kg}^{-1} ; \mathrm{P}, 23,4 \mathrm{mg} \mathrm{dm}{ }^{-3}$; 
teores de Al trocável, $\mathrm{K}, \mathrm{Ca}$ e $\mathrm{Mg}$ de 0,08, 0,06, 1,46 e $0,36 \mathrm{cmol}_{\mathrm{c}} \mathrm{dm}^{-3}$, respectivamente; capacidade de troca de cátions efetiva, $6,04 \mathrm{cmol}_{\mathrm{c}} \mathrm{dm}^{-3}$; saturação por bases, $32 \%$; densidade do solo, $1,50 \mathrm{Mg} \mathrm{m}^{-3}$; porosidade total, $0,37 \mathrm{~m}^{3} \mathrm{~m}^{-3}$; macroporosidade, $0,14 \mathrm{~m}^{3} \mathrm{~m}^{-3}$; e microporosidade, $0,23 \mathrm{~m}^{3} \mathrm{~m}^{-3}$.

$\mathrm{O}$ delineamento experimental foi feito em blocos completos ao acaso, com quatro repetições e parcelas de 6 × $10 \mathrm{~m}$. Avaliaram-se 11 tratamentos na entressafra da soja, alocados nas mesmas parcelas durante as três safras: 1, milheto, cultivares 'ADR 7010' (2010/2011) e 'ADR 300' (demais entressafras); 2, milho 'BRS 1010' (2010/2011) e 'GNZ 2005' (demais entressafras); 3, Crotalaria spectabilis; 4, C. spectabilis + milheto 'ADR 300'; 5, C. ochroleuca; 6, C. juncea; 7, braquiária ruziziensis (Urochloa ruziziensis); 8, capim-marandu ( $U$. brizantha 'Marandu'), 9, alqueive mecânico, controle de plantas daninhas por meio de duas gradagens, à profundidade de $0,1 \mathrm{~m}-\mathrm{a} 1 .^{\mathrm{a}}$ realizada logo após a colheita da soja, e a 2., 45 dias depois da colheita; o controle de plantas daninhas foi complementado por uma aplicação de glifosato (Roundup WG, 1,08 kg ha ${ }^{-1}$ de e.a.), aos 60 dias após a 2. gradagem; 10, alqueive químico (testemunha), controle de plantas daninhas com três aplicações de glifosato (Roundup WG, $1,08 \mathrm{~kg} \mathrm{ha}^{-1}$ de e.a.), realizadas nas mesmas datas das gradagens e da dessecação do tratamento 9, controle da soja voluntária, realizado 20 dias após a 1. aplicação de glifosato, por meio do arranque manual das plantas; e 11, pousio, sem controle das plantas daninhas. Por meio de avaliações visuais durante a entressafra, registraram-se as espécies de plantas daninhas predominantes no tratamento 11 (pousio). Nos tratamentos de 1 a 8 , o controle de plantas daninhas, durante a entressafra, foi realizado por meio de capina manual 20 dias após a semeadura. Os tratamentos foram conduzidos em sistema plantio direto, à exceção do alqueive mecânico. Na safra 2010/2011, o tratamento C. spectabilis + milheto não foi implantado, e as parcelas permaneceram em pousio na 2 a $^{\text {s }}$ safra. A semeadura das culturas de 2. a safra foi realizada em 22/02/2010, 26/02/2011 e 28/02/2012. Para a semeadura do milho, empregou-se uma semeadora tratorizada SHM 15/17 (Semeato, Passo Fundo, RS, Brasil), com linhas espaçadas em $0,9 \mathrm{~m}$, regulada para a obtenção de uma população de 55 mil plantas por hectare. A mesma semeadora foi utilizada para a implantação das demais culturas de
2. a safra, porém, com linhas espaçadas em $20 \mathrm{~cm}$ e distribuição de sementes por meio de dosador rotor acanalado, nas seguintes quantidades (sementes puras viáveis): milheto, $15 \mathrm{~kg} \mathrm{ha}^{-1}$; C. spectabilis, $12 \mathrm{~kg} \mathrm{ha}^{-1}$; C. ochroleuca, $6 \mathrm{~kg} \mathrm{ha}^{-1}$; C. juncea, $30 \mathrm{~kg} \mathrm{ha}^{-1}$; C. spectabilis + milheto, $12 \mathrm{e} 4 \mathrm{~kg} \mathrm{ha}^{-1}$, respectivamente; e braquiárias, $5 \mathrm{~kg} \mathrm{ha}^{-1}$. Apenas a cultura do milho foi adubada, tendo-se aplicado $15 \mathrm{~kg} \mathrm{ha}^{-1} \mathrm{de} \mathrm{N}$ e $60 \mathrm{~kg} \mathrm{ha}^{-1}$ de $\mathrm{P}_{2} \mathrm{O}_{5}$ e $\mathrm{K}_{2} \mathrm{O}$ (300 kg ha-1 de N-P $\mathrm{O}_{5}-\mathrm{K}_{2} \mathrm{O}$ 05-20-20), a lanço em pré-semeadura, e $67,5 \mathrm{~kg} \mathrm{ha}^{-1}$ de $\mathrm{N}$ na forma de ureia, em cobertura, 30 dias após a semeadura.

Todos os tratamentos foram submetidos a duas dessecações, realizadas 35 e 7 dias antes da semeadura da soja, por meio da aplicação do herbicida glifosato (Roundup WG), às doses de 1,44 e 0,72 kg ha ${ }^{-1}$ de e.a. nas $1 .^{\mathrm{a}} \mathrm{e} 2{ }^{\mathrm{a}}$ aplicações, respectivamente. A semeadura da soja foi realizada em 29/10/2010, 20/10/2011 e $12 / 11 / 2012$, em espaçamento de $0,5 \mathrm{~m}$, tendo-se obtido 250 mil plantas por hectare. As cultivares utilizadas foram a BRS Valiosa RR (2010/2011) e a M-Soy 9144 RR (2011/2012 e 2012/2013). As sementes foram tratadas com o inseticida Standak (fipronil, $25 \mathrm{~mL}$ de i.a. por $100 \mathrm{~kg}$ de sementes), o fungicida Vitavax-Thiram 200 $\mathrm{SC}$ (carboxina + tiram, $20+20 \mathrm{~mL}$ de i.a. por $100 \mathrm{~kg}$ de sementes) e, momentos antes da semeadura, aplicouse o inoculante líquido Rizo-Liq (Bradyrhizobium japonicum, estirpes Semia 5079 e 5080), à dose de $200 \mathrm{~mL}$ por $100 \mathrm{~kg}$ de sementes. A adubação consistiu da aplicação de $120 \mathrm{~kg} \mathrm{ha}^{-1}$ de $\mathrm{P}_{2} \mathrm{O}_{5}$, na forma de superfosfato triplo, a lanço, em pré-semeadura, e $100 \mathrm{~kg} \mathrm{ha}^{-1}$ de $\mathrm{K}_{2} \mathrm{O}$, na forma de cloreto de potássio, a lanço, aos 21 dias após a emergência. Os demais tratos culturais foram realizados conforme as indicações técnicas para a cultura na região.

A estimativa da população de $P$. brachyurus no solo foi realizada indiretamente por meio de bioensaios, conduzidos em casa de vegetação da Embrapa Soja, em Londrina, PR, em amostras de solo coletadas à profundidade $0-0,2 \mathrm{~m}$ de todas as parcelas, à época da implantação do experimento (fevereiro/2010), à semeadura (outubro/2010 e novembro/2012) e à colheita da soja (fevereiro/2011 e março/2013). Em cada época, o solo foi amostrado por parcela, em uma amostra composta por 10 subamostras. Para a realização dos bioensaios, $1 \mathrm{~kg}$ de solo de cada parcela foi transferido para um vaso de argila, onde foi transplantada uma plântula das cultivares de soja TMG115RR (fevereiro/2010), TMG131RR 
(outubro/2010 e fevereiro/2011) ou da linhagem PI 595099 (novembro/2012 e março/2013). Após o cultivo da soja por 60 dias, procedeu-se à extração e à contagem dos nematoides presentes nas raízes, conforme Coolen \& D'Herde (1972) e Goulart (2010). Nas safras 2010/2011 e 2012/2013, determinou-se o fator de reprodução (R) de $P$. brachyurus durante o ciclo da soja, conforme Oostenbrink (1966), para cada tratamento de entressafra. Embora o R tenha sido desenvolvido para comparar diferentes plantas quanto à reprodução do nematoide, no presente trabalho o $\mathrm{R}$ foi calculado também para o pousio e os alqueives mecânico e químico, por meio da razão entre as populações à época da colheita e à semeadura da soja.

Na safra 2011/2012, a população de $P$. brachyurus foi estimada diretamente em raízes de soja provenientes do ensaio de campo. Para isso, coletaram-se, ao acaso, os sistemas radiculares de 10 plantas de soja, por parcela, aos 45 e aos 90 dias após a semeadura (DAS). Em laboratório, as raízes foram pesadas e submetidas à extração (Coolen \& D'Herde, 1972; Goulart, 2010) e à contagem dos nematoides. Em todas as safras, a produtividade de grãos da soja foi determinada por meio da colheita mecânica da área útil da parcela $(4,5 \times 4,5 \mathrm{~m})$, e os dados foram corrigidos para $13 \%$ de umidade e expressos em quilogramas por hectare.

Os dados foram submetidos à análise da variância, pelo teste $\mathrm{F}$, a $5 \%$ de probabilidade. Em caso de efeito significativo de tratamento, as médias foram comparadas pelo teste de Scott-Knott, a 5\% de probabilidade. A relação das populações do nematoide com os valores de $\mathrm{R}$, à época da semeadura da soja, foi avaliada por meio de análise de regressão. Todas as análises estatísticas foram realizadas com o auxílio do programa estatístico SAS (SAS Institute Inc., Cary, NC, EUA).

\section{Resultados e Discussão}

A variabilidade da população de $P$. brachyurus no solo (bioensaio), antes da implantação do experimento (fevereiro/2010), foi aleatória, uma vez que não houve diferença entre os tratamentos (Tabela 1). Na amostragem realizada em outubro/2010, os tratamentos alqueive mecânico, C. spectabilis, C. ochroleuca e $C$. juncea reduziram a população de $P$. brachyurus em aproximadamente $60 \% \mathrm{em}$ relação à testemunha (alqueive químico). As maiores populações do nematoide foram observadas nos tratamentos milheto, braquiária ruziziensis, pousio, milho e capim-marandu, que não diferiram da testemunha. Em novembro/2012, as menores populações de $P$. brachyurus foram observadas nos tratamentos $C$. spectabilis, alqueive mecânico, C. ochroleuca, C. juncea, pousio e C. spectabilis + milheto, com redução de aproximadamente $75 \%$ em relação à testemunha. As maiores populações de $P$. brachyurus ocorreram nos tratamentos com as braquiárias ruziziensis e capim-marandu. O milho e o milheto hospedaram populações intermediárias de nematoides, mas sem diferir da observada na testemunha. Entretanto, à colheita da soja em ambas as safras, as populações de $P$. brachyurus no solo não foram influenciadas pelos tratamentos (Tabela 1).

Houve alteração da população de $P$. brachyurus nas raízes de soja, na safra 2011/2012, tanto aos 45 quanto aos 90 DAS (Tabela 2). As maiores diferenças foram observadas aos $45 \mathrm{DAS}$, com reduções das populações de nematoides nos tratamentos alqueive mecânico, C. ochroleuca, C. juncea, C. spectabilis e C. spectabilis + milheto. Em geral, observou-se redução da densidade populacional do nematoide em cerca de $60 \%$. O pousio, o milheto e a braquiária ruziziensis resultaram em densidades populacionais intermediárias, mas não diferiram da testemunha. Dos 45 aos 90 DAS, a população média do nematoide nas plantas de soja passou de 363 para 1.070 indivíduos por grama de raiz, o que representou um aumento de quase três vezes. Entretanto, as diferenças entre os tratamentos diminuíram ao longo do ciclo da soja. Assim, aos 90 DAS, apenas o tratamento braquiária ruziziensis, com a maior população de $P$. brachyurus nas raízes da soja, diferenciou-se dos demais. Esses resultados são compatíveis com aqueles obtidos dos bioensaios realizados nas safras 2010/2011 e 2012/2013, em que também não se verificaram diferenças entre os tratamentos quanto às populações de $P$. brachyurus no solo, por ocasião da colheita da soja (Tabela 1).

As alterações observadas nas populações do nematoide mostram que o cultivo de $C$. spectabilis ou de $C$. ochroleuca constitui prática cultural eficiente para reduzir $P$. brachyurus, durante a entressafra da soja, em condições de campo com alta infestação de nematoides e solo arenoso. Estes resultados corroboram os obtidos em estudos de casa de vegetação sobre a reação destas espécies ao nematoide (Inomoto et al.,

Pesq. agropec. bras., Brasília, v.51, n.10, p.1720-1728, out. 2016 DOI: $10.1590 / \mathrm{S} 0100-204 \mathrm{X} 2016001000003$ 
2006; Machado et al., 2007). Em experimento de campo com solo argiloso, em Lucas do Rio Verde, MT, Costa et al. (2014), também verificaram que o cultivo de $C$. spectabilis, na entressafra da soja, reduziu em aproximadamente $60 \%$ a densidade populacional de P. brachyurus, em comparação à testemunha capinada. O principal mecanismo envolvido na supressão dos nematoides pelas crotalárias é a capacidade que estas plantas apresentam de atuar como armadilhas, ou seja, de permitir a penetração nas suas raízes, nas fases juvenis, e de impedir o desenvolvimento subsequente do nematoide (Warnke et al., 2008; Curto et al., 2015). Além desse mecanismo, as plantas de crotalária acumulam metabólitos secundários com ação nematicida nas raízes, parte aérea e sementes, como o alcaloide pirrolizidínico denominado monocrotalina (Wang et al., 2002; Colegate et al., 2012). Além disso, a baixa relação $\mathrm{C}: \mathrm{N}$ das crotalárias possibilita a rápida decomposição da fitomassa, o que acelera a proliferação de microorganismos nematófagos (Wang et al., 2002).

No presente trabalho, a redução da densidade populacional de $P$. brachyurus no solo e nas raízes da soja, em consequência do cultivo de C. juncea na entressafra, foi similar à das demais espécies de crotalária (Tabela 1). Entretanto, os resultados obtidos em ensaios de casa de vegetação indicam que o cultivo de C. juncea, em geral, aumenta a população de
P. brachyurus (Machado et al., 2007; Santana-Gomes et al., 2014). Além da possível existência de variabilidade genética nas populações de $C$. juncea e $P$. brachyurus, as diferenças de eficiência observadas podem estar associadas à ausência, nos estudos em casa de vegetação, do efeito nematicida ou nematostático de substâncias presentes na parte aérea de $C$. juncea (Wang et al., 2002), já que a parte aérea das espécies testadas é geralmente descartada. Todavia, o estímulo à atividade de organismos nematófagos (Wang et al., 2002) e a liberação substâncias nematicidas (Colegate et al., 2012), a partir da decomposição da fitomassa da parte aérea de C. juncea, pode contribuir para o aumento da mortalidade do nematoide em condições de campo, em comparação aos ensaios de casa de vegetação. Neste sentido, reduções da população de nematoides fitófagos, após a aplicação de biomassa da parte aérea de $C$. juncea, foram observadas por Garrido et al. (2008) e Warnke et al. (2008).

$\mathrm{O}$ alqueive mecânico foi outra estratégia eficiente para diminuir a população do nematoide no solo, em comparação à testemunha, tendo-se equiparado ao tratamento com as crotalárias e com o consórcio C. spectabilis + milheto (Tabelas 1 e 2). Assim, a eliminação de plantas vivas pelo preparo do solo (aração/gradagem) resulta na morte dos nematoides por inanição (Goulart, 2008). Ademais, o preparo do solo favorece a exposição direta dos nematoides ao sol,

Tabela 1. Número de nematoides (Pratylenchus brachyurus) por planta de soja, estimado por meio de bioensaio em casa de vegetação, em amostras de solo coletadas à colheita (fevereiro/2010, fevereiro/2011 e março/2013) e à semeadura (outubro/2010 e novembro/2012) da soja, em razão do manejo adotado durante a entressafra, em Latossolo Vermelho Amarelo distrófico, no Município de Vera, $\mathrm{MT}^{(1)}$.

\begin{tabular}{|c|c|c|c|c|c|}
\hline \multirow[t]{2}{*}{ Manejo na entressafra } & \multicolumn{5}{|c|}{ Época de avaliação(2) } \\
\hline & Fev./2010 & Out./2010 & Fev./2011 & Nov./2012 & Mar./2013 \\
\hline Crotalaria spectabilis + milheto & $\mathrm{na}^{(3)}$ & na & na & $1.400 \mathrm{c}$ & $7.525 \mathrm{a}$ \\
\hline Pousio & $1.500 \mathrm{a}$ & $5.758 \mathrm{a}$ & $9.625 \mathrm{a}$ & $1.125 \mathrm{c}$ & $3.750 \mathrm{a}$ \\
\hline Milho & $1.680 \mathrm{a}$ & $5.812 \mathrm{a}$ & $14.125 \mathrm{a}$ & $3.500 \mathrm{~b}$ & $7.325 \mathrm{a}$ \\
\hline Milheto & $1.440 \mathrm{a}$ & $5.700 \mathrm{a}$ & $14.062 \mathrm{a}$ & $3.000 \mathrm{~b}$ & $7.950 \mathrm{a}$ \\
\hline Crotalaria ochroleuca & $1.340 \mathrm{a}$ & $1.350 \mathrm{~b}$ & $12.688 \mathrm{a}$ & $675 c$ & $4.600 \mathrm{a}$ \\
\hline Urochloa brizantha & $3.260 \mathrm{a}$ & $7.750 \mathrm{a}$ & $19.625 \mathrm{a}$ & $4.500 \mathrm{a}$ & $7.075 \mathrm{a}$ \\
\hline Alqueive químico & $2.900 \mathrm{a}$ & $4.050 \mathrm{a}$ & $12.188 \mathrm{a}$ & $2.800 \mathrm{~b}$ & $6.150 \mathrm{a}$ \\
\hline Crotalaria spectabilis & $2.720 \mathrm{a}$ & $1.112 b$ & $15.938 \mathrm{a}$ & $375 c$ & $7.825 \mathrm{a}$ \\
\hline Crotalaria juncea & $3.480 \mathrm{a}$ & $2.862 \mathrm{~b}$ & $13.812 \mathrm{a}$ & $900 \mathrm{c}$ & $6.675 \mathrm{a}$ \\
\hline Alqueive mecânico & $1.480 \mathrm{a}$ & $1.150 \mathrm{~b}$ & $8.250 \mathrm{a}$ & $375 \mathrm{c}$ & $3.875 \mathrm{a}$ \\
\hline Urochloa ruziziensis & $3.160 \mathrm{a}$ & $5.400 \mathrm{a}$ & $13.875 \mathrm{a}$ & $6.675 \mathrm{a}$ & $6.725 \mathrm{a}$ \\
\hline$\overline{\mathrm{CV}(\%)}$ & 61,1 & 69,0 & 50,2 & 51,0 & 39,0 \\
\hline
\end{tabular}

${ }^{(1)}$ Médias seguidas de letras iguais, nas colunas, não diferem pelo teste de Scott-Knott, a 5\% de probabilidade. ${ }^{(2)}$ Nos bioensaios, utilizaram-se as cultivares de soja TMG115RR (fev./2010) e TMG131RR (out./2010 e fev./2011) ou a linhagem PI 595099 (nov./2012 e mar./2013). ${ }^{(3)}$ Tratamento não avaliado. 
matando-os pela dessecação e pela ação nematicida dos raios ultravioletas (Inomoto, 2008). Esses dados contrariam os obtidos por Costa et al. (2014) que, em estudo de campo realizado sobre solo de textura argilosa, não encontraram diferenças significativas entre o preparo convencional com grade pesada e o sistema plantio direto, quanto à densidade populacional de $P$. brachyurus. Entretanto, apesar de ter-se mostrado uma prática cultural eficiente no controle de $P$. brachyurus, a adoção do alqueive mecânico pode ocasionar a degradação da qualidade do solo (Moraes et al., 2016) e a intensificação da erosão hídrica (Engel et al., 2009).

Trabalhos realizados em casa de vegetação têm mostrado que alguns genótipos de milheto apresentam baixos valores de R para $P$. brachyurus (Inomoto et al., 2007; Inomoto \& Asmus, 2010; Inomoto, 2011; Queiróz et al., 2014), e são, portanto, indicados como opções para rotação ou sucessão com a soja em áreas infestadas com esse nematoide (Dias et al., 2010). Entretanto, há pouca informação a respeito da eficiência do milheto em condições de campo, especialmente quando cultivado na entressafra, em solos arenosos e sob alta infestação de $P$. brachyurus. Os resultados obtidos no presente estudo mostraram que o semeadura das cultivares de millheto 'ADR 7010' (2010) e 'ADR 300' (2011 e 2012) não foi eficiente para reduzir a densidade

Tabela 2. Número de nematoides (Pratylenchus brachyurus) por grama de raízes de soja 'M-SOY 9144 RR', aos 45 e aos 90 dias após a semeadura na safra 2011/2012, em razão do manejo durante a entressafra em Latossolo Vermelho Amarelo distrófico, no Município de Vera, $\mathrm{MT}^{(1)}$.

\begin{tabular}{lcc}
\hline \multirow{2}{*}{ Manejo na entressafra } & \multicolumn{2}{c}{ Dias após a semeadura da soja } \\
\cline { 2 - 3 } & 45 & 90 \\
\hline Crotalaria spectabilis + milheto & $216 \mathrm{c}$ & $708 \mathrm{~b}$ \\
Pousio & $315 \mathrm{~b}$ & $852 \mathrm{~b}$ \\
Milho & $760 \mathrm{a}$ & $746 \mathrm{~b}$ \\
Milheto & $367 \mathrm{~b}$ & $884 \mathrm{~b}$ \\
Crotalaria ochroleuca & $155 \mathrm{c}$ & $1055 \mathrm{~b}$ \\
Urochloa brizantha & $824 \mathrm{a}$ & $1487 \mathrm{~b}$ \\
Alqueive químico & $443 \mathrm{~b}$ & $1081 \mathrm{~b}$ \\
Crotalaria spectabilis & $196 \mathrm{c}$ & $589 \mathrm{~b}$ \\
Crotalaria juncea & $167 \mathrm{c}$ & $1218 \mathrm{~b}$ \\
Alqueive mecânico & $114 \mathrm{c}$ & $334 \mathrm{~b}$ \\
Urochloa ruziziensis & $443 \mathrm{~b}$ & $2813 \mathrm{a}$ \\
\hline CV (\%) & 38,4 & 47,3 \\
\hline
\end{tabular}

(1)Médias seguidas por letras iguais, nas colunas, não diferem pelo teste de Scott-Knott, a 5\% de probabilidade. populacional de $P$. brachyurus, em comparação ao uso do alqueive químico (testemunha). Isto mostra que, sob altas populações iniciais e em condições que favorecem $P$. brachyurus (solo arenoso), o cultivo de genótipos de milheto com baixo $\mathrm{R}$ não se constitui na melhor opção para o controle deste nematoide na entressafra. Costa et al. (2014) verificaram que o cultivo de milheto 'ADR 300' também resultou em densidades populacionais de $P$. brachyurus similares às da testemunha (alqueive químico).

Os efeitos do consórcio C. spectabilis + milheto sobre a densidade populacional de P. brachyurus vêm sendo pouco estudados. No entanto, no presente estudo, a utilização do consórcio na entressafra reduziu a infestação de $P$. brachyurus a valores similares aos das crotalárias solteiras e às do alqueive mecânico (Tabelas 1 e 2) e constitui mais uma opção para o controle do nematoide na entressafra da soja.

Costa et al. (2014) verificaram que o pousio, durante a entressafra da soja, sem controle de plantas daninhas, resultou em aumentos da densidade populacional de $P$. brachyurus similares aos observados com o cultivo de um híbrido de milho suscetível ao nematoide. No presente trabalho, todavia, a população do nematoide no pousio foi similar (safras 2010/2011 e 2011/2012) ou inferior (safra 2012/2013) à população do tratamento testemunha (Tabelas 1 e 2). Possivelmente, as diferenças observadas nos dois experimentos, em relação à multiplicação de $P$. brachyurus no tratamento de pousio, encontram-se associadas a variações da composição florística da comunidade de plantas daninhas. No presente trabalho, predominaram as espécies trapoerabinha (Murdannia nudriflora) e, em menor infestação, o capim-colchão (Digitaria horizontalis). Costa et al. (2014) observaram predominância de capim-colchão, capim-marmelada (Brachiaria plantaginea) e leiteiro (Euphorbia heterophylla). A partir destas observações, verifica-se que são necessários mais estudos a respeito da reação de diferentes espécies de plantas daninhas à P. brachyurus.

Os resultados mostraram, ainda, que as braquiárias (ruziziensis e capim-marandu) e o milho foram os hospedeiros das maiores populações de P. brachyurus. Em ensaios de casa de vegetação, essas espécies de braquiária têm-se mostrado hospedeiras favoráveis a P. brachyurus (Inomoto et al., 2007; Inomoto \& Asmus, 2010; Queiróz et al., 2014), o que foi corroborado

Pesq. agropec. bras., Brasília, v.51, n.10, p.1720-1728, out. 2016 DOI: $10.1590 / \mathrm{S} 0100-204 \mathrm{X} 2016001000003$ 
pelos resultados no presente trabalho. Todavia, a multiplicação de $P$. brachyurus em milho depende do genótipo (Inomoto, 2011). Alguns híbridos, inclusive o utilizado no presente trabalho, nas safras 2011/2012 e 2012/2013 ('GNZ 2005'), apresentam baixos valores de R para P. brachyurus (Puerari et al., 2015). Entretanto, a utilização de um híbrido com baixo $\mathrm{R}$ não foi eficiente em reduzir a população do nematoide (Tabelas 1 e 2). Diferenças de agressividade de $P$. brachyurus - determinadas pela variabilidade genética entre populações do nematoide (Inomoto et al., 2007) bem como diferenças das condições ambientais, durante a realização dos ensaios, podem explicar essa discrepância. A menor duração dos ensaios em casa de vegetação, geralmente avaliados aos 60-90 dias após a inoculação (DAI), em comparação aos experimentos de campo, também pode conduzir a conclusões equivocadas quanto à capacidade de espécies vegetais em multiplicar o parasita. Por exemplo, Inomoto (2011) verificou que o $\mathrm{R}$ médio de três híbridos de milho para P. brachyurus aumentou de 2,04 aos 70 DAI, para 23,2 aos 107 DAI.

A redução das diferenças entre os tratamentos, ao longo do ciclo da soja (Tabelas 1 e 2), pode ser explicada pela maior multiplicação do nematoide, nos tratamentos mais eficientes quanto à diminuição da população, durante a entressafra (Figura 1). Neste contexto, o $\mathrm{R}$ do nematoide, durante o ciclo da soja, diminuiu em escala potencial com o aumento da população medida à época da semeadura da cultura, em ambas as safras (2010/2011 e 2012/2013). Na safra 2012/2013, a densidade populacional média de $P$. brachyurus, no tratamento C. spectabilis, passou de 375 indivíduos por planta à semeadura da soja, para 7.825 indivíduos por planta à colheita (Tabela 1), o que representa um $\mathrm{R}$ de aproximadamente 21. Já a população do nematoide no tratamento braquiária ruzizensis, à época da colheita da soja, foi similar à medida à época da semeadura da cultura, ou seja, um R próximo de 1,0. Outros estudos também indicam decréscimo do $\mathrm{R}$ com o aumento da população inicial do nematoide (Goulart et al., 2013), o que tem sido atribuído ao aumento da competição intraespecífica, principalmente por alimento.

A ausência de diferenças entre as densidades populacionais de $P$. brachyurus no solo, por ocasião da colheita da soja, indica a necessidade da repetição anual das práticas culturais adotadas na entressafra. Dias et al. (2010) explicam que a utilização de estratégias de manejo apenas na entressafra, mantendo-se o cultivo da soja durante a primavera/verão, pode não ser suficiente para reduzir a densidade populacional a níveis que possibilitem a produção econômica da soja semeada em seguida, principalmente em áreas arenosas e com alta infestação do parasita. Além de o tempo de adoção da estratégia ser menor (no máximo seis meses), a temperatura do ar e a umidade do solo na entressafra são menos favoráveis à eclosão dos juvenis do nematoide.

$\mathrm{Na}$ safra 2010/2011, o alqueive mecânico, as crotalárias, o pousio, o milheto e a braquiária ruziziensis promoveram produtividades de soja superiores às favorecidas pela testemunha, pelo milho e pelo capim-marandu, que não diferiram entre si (Tabela 3).
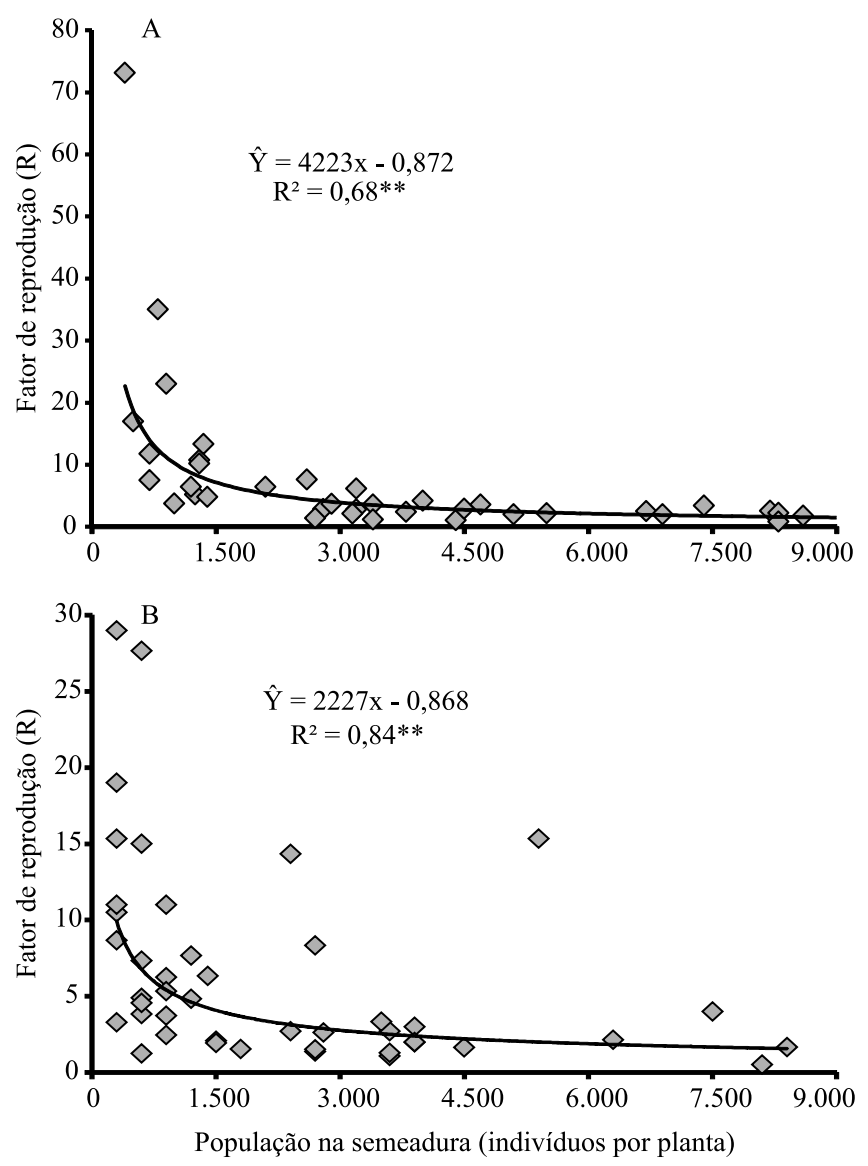

Figura 1. Relação do fator de reprodução (R) de Pratylenchus brachyurus, durante o ciclo da soja, com a população de nematoides à semeadura da cultura, nas safras 2010/2011 (A) e 2012/2013 (B), em Latossolo Vermelho Amarelo distrófico, no Município de Vera, MT. **Teste F significativo a $5 \%$ de probabilidade. 
Entre os tratamentos que favoreceram produtividade de soja superior à da testemunha, o alqueive mecânico e a $C$. spectabilis foram os que resultaram nos maiores valores. Não houve diferença de produtividade de soja entre os tratamentos na safra 2011/2012. Já na safra 2012/2013, a produtividade da soja, em consequência dos tratamentos C. spectabilis, milheto e C. spectabilis + milheto, foi maior do que a da testemunha e a dos demais manejos, que não diferiram entre si.

Apesar das menores populações iniciais de P. brachyurus (Tabelas 1 e 2), a produtividade da soja na safra 2012/2013, com os tratamentos C. ochroleuca, C. juncea e alqueive mecânico, foi inferior à do tratamento com milheto e similar à da testemunha, à do pousio, à das braquiárias e à do milho. Costa et al. (2014) também observaram que, apesar da maior densidade populacional de $P$. brachyurus, o cultivo de milheto e de Urochloa decumbens na entressafra contribuiu para produtividades de soja similares à resultante pelo tratamento com C. spectabilis e superiores à da testemunha capinada eà do pousio dessecado. Assim, fica evidente que a produtividade da soja não é determinada apenas pela população inicial de P. brachyurus no solo. Outros fatores, igualmente influenciados pelas práticas culturais adotadas na entressafra, devem implicar em maior ou menor tolerância da soja ao parasita. É provável

Tabela 3. Produtividade da soja nas safras 2010/2011, 2011/2012 e 2012/2013, em razão dos diferentes manejos adotados na entressafra, em Latossolo Vermelho Amarelo distrófico, no Município de Vera, $\mathrm{MT}^{(1)}$.

\begin{tabular}{lccc}
\hline Manejo & $2010 / 2011^{(2)}$ & $2011 / 2012^{(3)}$ & $2012 / 2013^{(3)}$ \\
\cline { 2 - 4 } & $-------------\left(\mathrm{kg} \mathrm{ha}^{-1}\right)------------$ \\
\hline Crotalaria spectabilis + milheto & $\mathrm{na}^{(4)}$ & $2.451 \mathrm{a}$ & $3.015 \mathrm{a}$ \\
Pousio & $1.971 \mathrm{~b}$ & $2.342 \mathrm{a}$ & $2.355 \mathrm{~b}$ \\
Milho & $1.599 \mathrm{c}$ & $2.005 \mathrm{a}$ & $2.317 \mathrm{~b}$ \\
Milheto & $1.996 \mathrm{~b}$ & $2.375 \mathrm{a}$ & $2.937 \mathrm{a}$ \\
Crotalaria ochroleuca & $1.955 \mathrm{~b}$ & $2.029 \mathrm{a}$ & $2.311 \mathrm{~b}$ \\
Urochloa brizantha & $1.451 \mathrm{c}$ & $2.035 \mathrm{a}$ & $2.196 \mathrm{~b}$ \\
Alqueive químico & $1.373 \mathrm{c}$ & $1.926 \mathrm{a}$ & $2.183 \mathrm{~b}$ \\
Crotalaria spectabilis & $2.485 \mathrm{a}$ & $2.208 \mathrm{a}$ & $2.670 \mathrm{a}$ \\
Crotalaria juncea & $1.946 \mathrm{~b}$ & $2.294 \mathrm{a}$ & $1.901 \mathrm{~b}$ \\
Alqueive mecânico & $2.520 \mathrm{a}$ & $2.195 \mathrm{a}$ & $2.150 \mathrm{~b}$ \\
Urochloa ruziziensis & $1.977 \mathrm{~b}$ & $2.066 \mathrm{a}$ & $2.000 \mathrm{~b}$ \\
\hline Média & 1.927 & 2.175 & 2.365 \\
CV (\%) & 12,2 & 13,3 & 11,3 \\
\hline
\end{tabular}

(1)Médias seguidas de letras iguais, nas colunas, não diferem pelo teste de Scott-Knott, a 5\% de probabilidade. ${ }^{(2)}$ Cultivar de soja BRS Valiosa RR.

${ }^{(3)}$ Cultivar de soja M-Soy 9144 RR. ${ }^{(4)}$ Tratamento não avaliado. que a maior cobertura do solo proporcionada pelas gramíneas, principalmente o milheto e as braquiárias, tenha contribuído para aumentar a disponibilidade de água, tornando a soja mais tolerante ao nematoide (Dias et al, 2010). Isso é ainda mais importante em solos arenosos, com baixa capacidade de retenção de água, como o utilizado no presente trabalho. Assim, o consórcio do milheto, gramínea com alto potencial de produção de fitomassa da parte aérea (Soratto et al., 2012), com C. spectabilis, pode trazer o aumento da cobertura do solo, como benefício adicional à redução da população de $P$. brachyurus e garantir, assim, maiores produtividades de soja, sobretudo em solos arenosos.

\section{Conclusões}

1. O alqueive mecânico e o cultivo de Crotalaria spectabilis, C. ochroleuca, C. juncea ou do consórcio C. spectabilis + milheto 'ADR 300', durante a entressafra da soja, reduzem a densidade populacional de Pratylenchus brachyurus no solo.

2. A multiplicação de $P$. brachyurus durante o ciclo da soja aumenta com a redução da população do nematoide à semeadura, de modo que, após a colheita, as diferenças entre os manejos na entressafra tornamse pequenas.

3. O cultivo da $C$. spectabilis na entressafra, solteira ou consorciada com o milheto 'ADR 300', reduz a população e os danos causados por $P$. brachyurus à soja.

\section{Referências}

CASTILlO, P.; VOVLAS, N. Pratylenchus (Nematoda: Pratylenchidae): diagnosis, biology, pathogenicity and management. Leiden: Brill, 2007. 529p. (Nematology Monographs \& Perspectives, 6). DOI: 10.1163/ej.9789004155640.i-523.

COLEGATE, S.M.; GARDNER, D.R.; JOY, R.J.; BETZ, J.M.; PANTER, K.E. Dehydropyrrolizidine alkaloids, including monoesters with an unusual esterifying acid, from cultivated Crotalaria juncea (sunn hemp cv. 'Tropic Sun'). Journal of Agricultural and Food Chemistry, v.60, p.3541-3550, 2012. DOI: $10.1021 /$ jf205296s.

COOLEN, W.A.; D'HERDE, C.J. A method for the quantitative extraction of nematodes from plant tissue. Gent: State Agricultural Research Center, 1972. 77p.

COSTA, M.J.N. da; PASQUALLI, R.M.; PREVEDELLO, R. Efeito do teor de matéria orgânica do solo, cultura de cobertura e sistema de plantio no controle de Pratylenchus brachyurus em soja. Summa Phytopathologica, v.40, p.63-70, 2014. DOI: 10.1590/S0100-54052014000100009. 
CURTO, G.; DALlaVAlle, E.; SANTI, R.; CASADEI, N.; D'AVINO, L.; LAZZERI, L. The potential of Crotalaria juncea $\mathrm{L}$. as a summer green manure crop in comparison to Brassicaceae catch crops for management of Meloidogyne incognita in the Mediterranean area. European Journal of Plant Pathology, v.142, p.829-841, 2015. DOI: 10.1007/s10658-015-0655-2.

DIAS, W.P.; ASMUS, G.L.; SILVA, J.F.V; GARCIA, A.; CARNEIRO, G.E. de S. Nematoides. In: ALMEIDA, A.M.R.; SEIXAS, C.D.S. (Ed.). Soja: doenças radiculares e de hastes e inter-relações com o manejo do solo e da cultura. Londrina: Embrapa Soja, 2010. p.173-206.

ENGEL, F.L.; BERTOL, I.; RITTER, S.R.; PAZ GONZÁLEZ, A.; PÁZ-FERREIRO, J.; VIDAL VÁZQUEZ, E. Soil erosion under simulated rainfall in relation to phenological stages of soybeans and tillage methods in Lages, SC, Brazil. Soil and Tillage Research, v.103, p.216-221, 2009. DOI: 10.1016/j.still.2008.05.017.

FRANCHINI, J.C.; DEBIASI, H.; DIAS, W.P.; RAMOS JUNIOR, E.U.; SILVA, J.F.V. Perda de produtividade da soja em área infestada por nematoidedaslesõesradiculares na região médionorte do Mato Grosso. In: BERNARDI, A. C. de C.; NAIME, J. de M.; RESENDE, A.V. de; BASSOI, L.H.; INAMASU, R.Y. (Ed.). Agricultura de precisão: resultados de um novo olhar. Brasília: Embrapa, 2014. p.274-278.

GARRIDO, M. da S.; SOARES, A.C.F.; COIMBRA, J.L.; SOUSA, C. da S. Management of crotalaria and pigeon pea for control of yam nematode diseases. Summa phytopathologica, v.34, p.222-227, 2008. DOI: 10.1590/S0100-54052008000300003.

GOULART, A.M.C. Análise nematológica: importância e princípios gerais. Planaltina: Embrapa Cerrados, 2010. 45p. (Embrapa Cerrados. Documentos, 299).

GOULART, A.M.C. Aspectos gerais sobre nematóides-das-lesões-radiculares (gênero Pratylenchus). Planaltina: Embrapa Cerrados, 2008. 30p. (Embrapa Cerrados. Documentos, 219).

GOULART, M.M.P.; CARMO, E.L.; SANTOS, C.B.; SILVA, V.R.; CAMPOS, H.D. Avaliação do efeito de diferentes populações de Pratylenchus brachyurus na cultura da soja. Global Science and Technology, v.6, p.8-14, 2013. DOI: 10.14688/1984-3801. v06n02a01.

INOMOTO, M.M.; ASMUS, G.L. Host status of graminaceous cover crops for Pratylenchus brachyurus. Plant Disease, v.94, p.1022-1025, 2010.

INOMOTO, M.M.; MOTTA, L.C.C.; BELUTI, D.B.; MACHADO, A.C.Z. Reação de seis adubos verdes a Meloidogyne javanica e Pratylenchus brachyurus. Nematologia Brasileira, v.30, p.39-44, 2006.

INOMOTO, M.M.; MACHADO, A.C.Z.; ANTEDOMÊNICO, S.R. Reação de Brachiaria spp. e Panicum maximum a Pratylenchus brachyurus. Fitopatologia Brasileira, v.32, p.341-344, 2007.
INOMOTO, M.M. Importância e manejo de Pratylenchus brachyurus. Revista Plantio Direto, v.108, p.4-9, 2008.

INOMOTO, M.M. Avaliação da resistência de 12 híbridos de milho a Pratylenchus brachyurus. Tropical Plant Pathology, v.36, p.308-312, 2011. DOI: 10.1590/S1982-56762011000500006.

MACHADO, A.C.Z.; MOTTA, L.C.C.; SIQUEIRA, K.M.S. de; FERRAZ, L.C.C.B.; INOMOTO, M.M. Host status of green manures for two isolates of Pratylenchus brachyurus in Brazil. Nematology, v.9, p.799-805, 2007. DOI: $10.1163 / 156854107782331153$.

MORAES, M.T. de; DEBIASI, H.; CARLESSO, R.; FRANCHINI, J.C.; SILVA, V.R. da; LUZ, F.B. da. Soil physical quality on tillage and cropping systems after two decades in the subtropical region of Brazil. Soil and Tillage Research, v.155, p.351-362, 2016. DOI: 10.1016/j.still.2015.07.015.

OOSTENBRINK, M. Major characteristics of relations between nematodes and plants. Mededelingen Landbouwhogeschool, v.66, p.1-46, 1966.

PUERARI, H.H.; DIAS-ARIEIRA, C.R.; CARDOSO, M.R.; HERNANDES, I.; BRITO, O.D.C. Resistance inducers in the control of root lesion nematodes in resistant and susceptible cultivars of maize. Phytoparasitica, v.43, p.383-389, 2015. DOI: 10.1007/s12600-014-0447-9.

QUEIRÓZ, C. de A.; FERNANDES, C.D.; VERZIGNASSI, J.R.; VALLE, C.B. do; JANK, L.; MALLMANN, G.; BATISTA, M.V. Reação de acessos e cultivares de Brachiaria spp. e Panicum maximum à Pratylenchus brachyurus. Summa Phytopathologica, v.40, p.226-230, 2014. DOI: 10.1590/0100-5405/1899.

RIBEIRO, N.R.; DIAS, W.P.; SANTOS, J.M. dos. Distribuição de fitonematóides em regiões produtoras de soja do Estado de Mato Grosso. Boletim de Pesquisa de Soja, n.14, p.289-296, 2010.

SANTANA-GOMES, S. de M.; DIAS-ARIEIRA, C.R.; BIELA, F.; CARDOSO, M.R.; FONTANA, L.F.; PUERARI, H.H. Sucessão de culturas no manejo de Pratylenchus brachyurus em soja. Nematropica, v.44, p.200-206, 2014.

SORATTO, R.P.; CRUSCIOL, C.A.C.; COSTA, C.H.M. da; FERRARI NETO, J.; CASTRO, G.S.A. Produção, decomposição e ciclagem de nutrientes em resíduos de crotalária e milheto, cultivados solteiros e consorciados. Pesquisa Agropecuária Brasileira, v.47, p.1462-1470, 2012. DOI: 10.1590/ S0100-204X2012001000008.

WANG, K.-H.; SIPES, B.S.; SCHMITT, D.P. Crotalaria as a cover crop for nematode management: a review. Nematropica, v.32, p. 35-57, 2002.

WARNKE, S.A.; CHEN, S.; WYSE, D.L.; JOHNSON, G.A.; PORTER, P.M. Effect of rotation crops on hatch, viability and development of Heterodera glycines. Nematology, v.10, p.869-882, 2008. DOI: 10.1163/156854108786161391.

Recebido em 26 de janeiro de 2016 e aprovado em 14 de junho de 2016

Pesq. agropec. bras., Brasília, v.51, n.10, p.1720-1728, out. 2016

DOI: 10.1590/S0100-204X2016001000003 